\title{
Identification and sequence analysis of IS6501, an insertion sequence in Brucella spp.: relationship between genomic structure and the number of IS6501 copies
}

\author{
Safia Ouahrani, Sylvie Michaux, Joannes Sri Widada, Gisele Bourg, Regis Tournebize, \\ Michel Ramuz and Jean-Pierre LiautarD*
}

INSERM U-65, Departement Biologie Santé, C.P. 100, Université de Montpellier II, Place E. Bataillon, 34095 Montpellier, France

(Received 10 March 1993; revised 22 July 1993; accepted 28 July 1993)

\begin{abstract}
An insertion sequence (IS) element of Brucella ovis, named IS6501, was isolated and its complete nucleotide sequence determined. IS6501 is $836 \mathrm{bp}$ in length and occurs 20-35 times in the B. ovis genome and 5-15 times in other Brucella species. Analysis of the junctions at the sites of insertion revealed a small target site duplication of four bases and inverted repeats of 17 bp with one mismatch. IS6501 presents significant similarity (53.4\%) with IS427 identified in Agrobacterium tumefaciens, suggesting a common ancestral sequence. A long ORF of 708 bp was identified encoding a protein with a predicted molecular mass of $26 \mathrm{kDa}$ and sharing sequence identity with the hypothetical protein 1 of $A$. tumefaciens and with the transposase of Mycobacterium tuberculosis. IS6501 is present in all Brucella strains we have tested. Restriction fragment length polymorphism of reference and field strains of two species (B. melitensis and B. ovis) was studied using either pulsed field gel electrophoresis (PFGE) on XbaI-digested DNA or hybridization of EcoRI-digested DNA using IS6501 as a probe. The genome of $B$. melitensis biovar 3 contains about 10 IS copies per genome and field strains of the same species could not be distinguished either by IS hybridization or by XbaI (PFGE) restriction patterns. In contrast, the number of IS copies in the B. ovis genome is around 30 and the different field strains can be differentiated by both methods. As ISs have been shown to be implicated in chromosomal rearrangement, we propose that the chromosomal polymorphism revealed by PFGE and high copy number of IS6501 observed in B. ovis may be related to the presence of an active IS in this species.
\end{abstract}

\section{Introduction}

Bacteria of the genus Brucella are Gram-negative facultative intracellular pathogens that cause infections in animals and humans. The genus comprises six individualized groups, often considered as species $(B$. abortus, $B$. canis, $B$. melitensis, B. neotomae, $B$. ovis and $B$. suis), named according to their preferential hosts

*Author for correspondence. Tel. +3367143209 ; fax +336714 3338 .

Abbreviations: IHF, integration host factor; IS, insertion sequence; PFGE, pulsed field gel electrophoresis; RFLP, restriction fragment length polymorphism.

The nucleotide sequence data reported in this paper have been submitted to EMBL and have been assigned the accession number X71024.
(Corbel \& Brinley-Morgan, 1984). The different nomen species are classified according to their metabolic phenotypes and dye and phage sensitivity (Meyer \& Cameron, 1961). However, on the basis of DNA analysis, measured by hybridization, Verger et al. (1985) have proposed that the genus is comprised of only one species $B$. melitensis. This proposition is strengthened by the rarity of genes that show restriction fragment length polymorphism (RFLP) and the very high conservation of the sequence of $h s p 60$ in different species (unpublished results). In contrast, we have shown (Allardet-Servent $e t$ al., 1988) that a substantial polymorphism can be detected when the genome of Brucella species is analysed by pulsed field gel electrophoresis (PFGE) using several rare cutting restriction endonucleases.

Using PCR on the gene encoding the BCSP31 protein, characterized by Mayfield et al. (1988) for its antigenic character, an insertion sequence (IS6501) was observed 
Table 1. Brucella strains

\begin{tabular}{|c|c|c|c|c|}
\hline Species & Biovar & Strain* & Host & Geographic origin \\
\hline B. melitensis & $\begin{array}{l}\text { M1 } \\
\text { M2 } \\
\text { M3 }\end{array}$ & $\begin{array}{l}16 \mathrm{M}^{\mathrm{T}}(\mathrm{ATCC} 23456) \\
63 / 9(\mathrm{ATCC} 23457) \\
\text { Ether (ATCC 23458) } \\
1381 \\
1572 \\
1574 \\
1575 \\
1577 \\
1578 \\
1590\end{array}$ & $\begin{array}{l}\text { Goat } \\
\text { Goat } \\
\text { Goat } \\
\text { Cattle } \\
\text { Human } \\
\text { Human } \\
\text { Sheep } \\
\text { Human } \\
\text { Sheep } \\
\text { Human }\end{array}$ & $\begin{array}{l}\text { USA } \\
\text { Turkey } \\
\text { Italy } \\
\text { France (Gap) } \\
\text { France (Toulon) } \\
\text { France (Marseille) } \\
\text { France (Avignon) } \\
\text { France (Paris) } \\
\text { France (Draguignan) } \\
\text { France (St Dié) }\end{array}$ \\
\hline B. abortus & $\begin{array}{l}\text { A1 } \\
\text { A2 } \\
\text { A3 } \\
\text { A4 } \\
\text { A5 } \\
\text { A6 } \\
\text { A9 }\end{array}$ & $\begin{array}{l}544^{\mathrm{T}}(\text { ATCC } 23448) \\
86 / 8 / 59(\text { ATCC } 23449) \\
\text { Tulya (ATCC } 23450) \\
292(\text { ATCC } 23451) \\
\text { B3196 (ATCC 23452) } \\
870(\text { ATCC } 23453) \\
\text { C68 (ATCC 23455) }\end{array}$ & $\begin{array}{l}\text { Cattle } \\
\text { Cattle } \\
\text { Human } \\
\text { Cattle } \\
\text { Cattle } \\
\text { Cattle } \\
\text { Cattle }\end{array}$ & $\begin{array}{l}\text { England } \\
\text { England } \\
\text { Uganda } \\
\text { England } \\
\text { England } \\
\text { Africa } \\
\text { England }\end{array}$ \\
\hline B. suis & $\begin{array}{l}\text { S1 } \\
\text { S2 } \\
\text { S3 } \\
\text { S4 }\end{array}$ & $\begin{array}{l}1330^{\mathrm{T}}(\text { ATCC } 23444) \\
\text { Thomsen }(\text { ATCC } 23445) \\
686(\text { ATCC } 23446) \\
40(\text { ATCC } 23447)\end{array}$ & $\begin{array}{l}\text { Swine } \\
\text { Swine } \\
\text { Swine } \\
\text { Reindeer }\end{array}$ & $\begin{array}{l}\text { USA } \\
\text { Denmark } \\
\text { USA } \\
\text { USSR }\end{array}$ \\
\hline B. canis & & $63 / 290^{\mathrm{T}}($ ATCC 23365$)$ & Dog & USA \\
\hline B. ovis & & $\begin{array}{l}\text { RM6 } / 66^{\mathrm{T}}(\text { ATCC 25840) } \\
76 / 247 \\
76 / 250 \\
91 / 66 \\
91 / 70 \\
91 / 208 \\
91 / 212 \\
91 / 217 \\
91 / 264 \\
91 / 266 \\
91 / 268\end{array}$ & Sheep & $\begin{array}{l}\text { Africa } \\
\text { France (Toulon) } \\
\text { France (Biarritz) } \\
\text { Spain (Aragon) } \\
\text { Spain (Aragon) } \\
\text { Spain (Bilbao) } \\
\text { Spain (Bilbao) } \\
\text { Spain (Bilbao) } \\
\text { Argentina } \\
\text { Argentina } \\
\text { Switzerland }\end{array}$ \\
\hline
\end{tabular}

* Type strains and biovar reference strains are listed by their FAO/WHO designation and their American Type Culture Collection numbers. Field strains of $B$. melitensis are listed by the numbers of the culture collection of Montpellier (France) and those of $B$. ovis by the number of INRANouzilly collection (Tours, France).

downstream of the B. ovis BCSP31 gene. However, this IS is absent downstream of the BCSP31 gene in other species of Brucella. Such a sequence was also observed by Halling \& Zehr (1990). This IS was isolated, its nucleotide sequence determined and its distribution analysed in the different nomen species of Brucella. Diversity found by PFGE correlates well with the polymorphism revealed by RFLP using IS6501 as a probe.

\section{Methods}

Bacterial strains and culture conditions. Brucella strains used in this study are listed in Table 1. Reference strains of B. melitensis biovar 3 and $B$. ovis were obtained from the American Type Culture Collection, Rockville, MD, USA. B. ovis field strains were provided by Dr J. P. Verger, INRA, Nouzilly-les-Tours, France. The other strains originate from the reference laboratory of Montpellier (France). Cultures were grown on Brucella agar (Difco) at $37^{\circ} \mathrm{C}$ for $72 \mathrm{~h}$. Cells were harvested by centrifugation, then washed twice with TE buffer and stored at $-20^{\circ} \mathrm{C}$ until extraction of DNA.

Preparation of genomic DNA and plasmid vector. Total DNA was extracted from the different strains of Brucella using the procedure described for Gram-negative bacteria by Ausubel et al. (1987). Escherichia coli XL-1 Blue competent cells and plating cultures were prepared as described by Sambrook et al. (1989) for use as a host for plasmid pBSIIKS + purchased from Stratagene (pBluescriptII Exo/ mung Kit). They were processed as described previously (Cellier $e t$ al., 1992).

Polymerase chain reaction $(P C R)$ and oligonucleotide selection. Starting with the sequence of the BCSP31 gene published by Mayfield et al. (1988), three oligonucleotides were selected to generate fragments of either $350 \mathrm{bp}$ or $710 \mathrm{bp}$ by using oligonucleotides I and II or I and III, respectively. Oligonucleotide I (5' GTATCGTTCTTGAAGCCTAC $3^{\prime}$ ) is 20 bases in length and starts at base 1055; oligonucleotide II (5' CCTTGGTGATGTTATAGATG 3'), complementary to the coding sequence, is 20 bases in length and starts at base 1405; oligonucleotide III ( $5^{\prime}$ GTGCATTTCAATAGGCTAGAG 3'), complementary to the coding sequence, is 21 bases in length and starts at 
base 1765. Amplification of DNA was performed in a total volume of $50 \mu 1$ in $1 \times$ Taq-DNA-Polymerase buffer (Promega) with 50 pmol of each primer, $0.2 \mathrm{~mm}$ of each deoxynucleotide triphosphate (dATP, dCTP, dGTP, dTTP), $2.5 \mathrm{U}$ of Taq DNA polymerase (Promega) and $100 \mathrm{ng}$ of target DNA. The mixture was overlaid with $50 \mu \mathrm{l}$ of mineral oil and subjected to 30 cycles of amplification as follows: denaturation at $95^{\circ} \mathrm{C}$ for $35 \mathrm{~s}$, annealing at $56^{\circ} \mathrm{C}$ for $45 \mathrm{~s}$ and extension at $72{ }^{\circ} \mathrm{C}$ for $45 \mathrm{~s}$. Thermal cycling was performed in a PCR processor trio thermo bloc (Biometra). Five percent of amplified DNA was analysed by $1.5 \%$ agarose gel electrophoresis.

Molecular cloning and DNA sequence analysis. Molecular cloning techniques were carried out as described by Sambrook et al. (1989). The 1600 bp fragment amplified by PCR was cloned in pBSIIKS + and sequenced using a sequencing kit (USB) according to the manufacturer's instructions using a commercially available primer (Stratagene). Sequencing gels were $8 \%(\mathrm{w} / \mathrm{v})$ polyacrylamide containing $8 \mathrm{M}$ urea. The sequence data were compiled and analysed using the DNA analysis program MBS (Macro/Bio/Soft) purchased from Prolabo (France).

Cloning and screening of other copies of the IS. A genomic library of B. ovis DNA was constructed in pBSIIKS + to isolate ISs. Total DNA was digested by HindIII and ligated into HindIII sites of pBS. E. coli cells were transformed by electroporation with a Cellject system (Eurogentec) and spread on LB plates containing $\left(\mathrm{ml}^{-1}\right) 100 \mu \mathrm{g}$ ampicillin, $25 \mu \mathrm{g}$ tetracycline, $2 \mathrm{~mm}-\mathrm{IPTG}$ and $400 \mu \mathrm{m}-\mathrm{XGal}$, and grown overnight at $37^{\circ} \mathrm{C}$. White colonies were picked to 96 -well plates (Falcon), grown overnight in LB plus ampicillin and stored in $50 \%$ (v/v) glycerol at $-20^{\circ} \mathrm{C}$. Colony blots were carried out using GeneScreen Plus nylon membranes as recommended by the supplier (New England Biolabs). IS6501 was radiolabelled in vitro using a random priming kit (Boehringer Mannheim) with $\left[\alpha-{ }^{32} \mathrm{P}\right] \mathrm{dCTP}$, according to the supplier's protocol. Prehybridization and hybridization were performed at $42{ }^{\circ} \mathrm{C}$ in $50 \%(\mathrm{v} / \mathrm{v})$ formamide. The membranes were washed briefly twice in $2 \times \mathrm{SSC}$ at room temperature $(1 \times \mathrm{SSC}$ is $150 \mathrm{~mm}-\mathrm{NaCl}, 15 \mathrm{~mm}$-sodium citrate dihydrate, $\mathrm{pH} 7 \cdot 0)$, twice in $2 \times$ SSC with $1 \%(\mathrm{w} / \mathrm{v}) \mathrm{SDS}$ and $50 \%$ formamide for $30 \mathrm{~min}$ at $37^{\circ} \mathrm{C}$, and twice with $0.1 \times \mathrm{SSC}$ for $30 \mathrm{~min}$ at room temperature followed by autoradiography on Fuji X-ray medical films. Positive clones were analysed by restriction analysis. They were also sequenced, using pBS primers and primers calculated from IS6501.

RFLP. Preparation, digestion by $X b a \mathrm{I}$ and PFGE of genomic Brucella DNA were performed as described previously (AllardetServent et al., 1991; Michaux et al., 1993). EcoRI-digested DNA was separated by conventional electrophoresis. The IS6501 probe was labelled by a non-isotopic method (Boehringer Mannheim) and hybridized as recommended by the manufacturer.

Computer analysis. The Macro/Bio/Soft package (Prolabo, France) was used for routine sequence analysis. BISANCE (Dessen et al., 1990) was used for on-line analysis.

\section{Results}

\section{Evidence for an IS in the PCR products}

The nucleotide sequence of the BCSP31 gene, which was cloned and sequenced by Mayfield et al. (1988), was used to develop a specific diagnostic test based on PCR. Amplifications performed with oligonucleotides I and II (see Methods) generated a unique fragment of $350 \mathrm{bp}$ in all five species of Brucella tested. However, when oligonucleotides I and III were used, a fragment of $750 \mathrm{bp}$ was amplified for all species of Brucella except for $B$. ovis where a fragment of $1600 \mathrm{bp}$ was observed (Fig. 1). A DNA fragment of about $900 \mathrm{bp}$ is inserted at this location in the genome of $B$. ovis. Southern blot analysis of the genomic DNA, using the $B$. ovis amplified fragment as a probe, revealed more than 20 bands (see Fig. 5). This implied that the DNA inserted in the genome of $B$. ovis is analogous to an IS. To confirm this finding it was necessary to sequence it.

\section{Characterization of the IS}

Whilst we were studying these PCR products, Halling \& Zehr (1990) described a similar insertion element of approximately $0.9 \mathrm{~kb}$ at a site downstream of the BCSP31 coding region in strains of $B$. ovis. However, they gave no details about its nature, sequence analysis, site of insertion, or its distribution in other species of Brucella.

To characterize the $1600 \mathrm{bp}$ fragment amplified by PCR, a restriction map was made. No sites were found for BamHI, ClaI, EcoRI, EcoRV or PstI (data not shown). HindIII generated two fragments of 1000 and 600 bp. Digestion by HinfI gave a profile similar to that described by Halling \& Zehr (1990). The PCR products whose sizes were 350 and $710 \mathrm{bp}$, respectively, were sequenced directly using the amplification primers. As the $1600 \mathrm{bp}$ fragment amplified with $B$. ovis was too long to be sequenced using this method, we cloned it in pBSIIKS + . Firstly, HindIII linkers were added to its extremities by ligation. HindIII digestion gave rise to two fragments of 1000 and $600 \mathrm{bp}$ which were then cloned separately in the HindIII site of pBSIIKS +. The resultant clones were sequenced in both directions using the primers T3, KS, SK and T7 of the pBS vector and the PCR oligonucleotides (I, II, III). The sequences obtained were aligned and compared with the BCSP31 gene nucleotide sequence using the DNA analysis program MBS. The deduced nucleotide sequence of the IS element, named IS6501, is presented in Fig. 2.

To confirm the sequence, to identify the exact duplication target site, to determine the flanking regions, and to know if the sequenced element is the same in the B. ovis genome, other copies were cloned and sequenced. A DNA library was screened with the IS6501 probe. The restriction enzyme site profiles of positive clones were characterized and Southern blot hybridizations were used to confirm the presence of IS6501 (data not shown). Twenty isolates were identified and sequenced. The data were aligned for comparison. In these clones, the sequences of IS6501 with its inverted repeats and its direct repeats were the same. However, in the flanking regions of IS6501 (Fig. 3), no specific consensus sequence between these clones was found. 


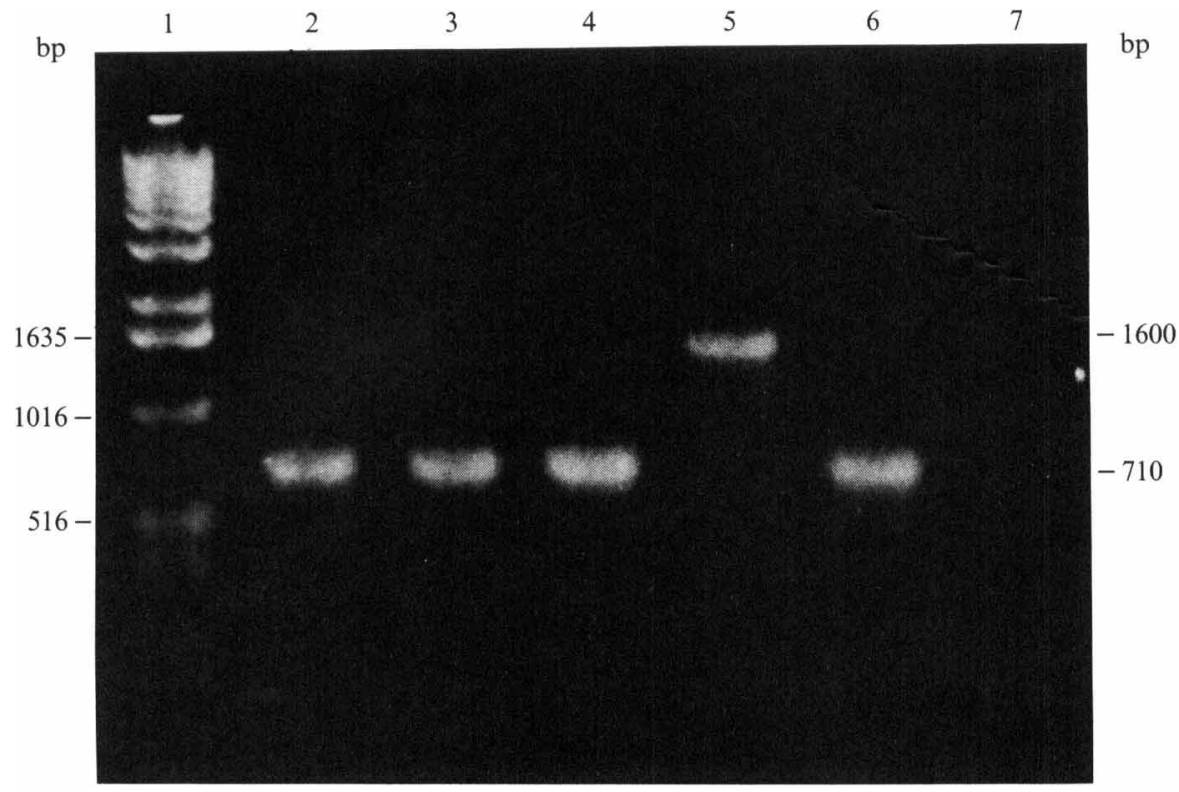

Fig. 1. Agarose gel electrophoresis of DNA fragments obtained by PCR with oligonucleotides I and III. Lanes: 1 , molecular size standard (1 kb ladder, BRL); 2, B. abortus; $3, B$. canis; 4, B. melitensis $16 \mathrm{M} ; 5, B$. ovis; $6, B$. suis; 7 , negative control. The size of amplified fragments is indicated on the right. No amplification was observed with the negative control.

\section{Sequence analysis of IS650I}

The nucleotide sequence of IS6501 is 836 bp long and is flanked by two $17 \mathrm{bp}$ inverted repeats with one mismatch (Fig. 2). At the site of insertion, $4 \mathrm{bp}$ target DNA duplications are generated (CTAG). The sequence of four flanking genes is presented in Fig. 3. It appears that no specific sequence or base composition is obvious around the insertion site. However, at the $5^{\prime}$ end some bases are shared by the four sequences. The significance of this observation is difficult to assess.

Three consensus IHF (integration host factor) sites (AANNNNTTGAT) are present in IS6501. Five Dammethylase sites (GATC) are also present (Fig. 2).

A computer search in the Genbank/EMBL database revealed 53.8\% sequence identity with IS427 of Agrobacterium tumefaciens over 742 bp (De Meirsman et al., 1990) (data not shown). No other significant sequence homology has been found with other sequenced ISs present in the database. Unexpectedly, although a high degree of similarity was found with IS427 of $A$. tumefaciens, the ORFs are localized differently and no real homology was detected at the protein level. Numerous deletions (or insertions) of one or two nucleotides appear between the two sequences breaking the reading frame in $A$. tumefaciens.

\section{Analysis of the putative transposase}

A major ORF of 236 amino acids is revealed by computer analysis with a putative Shine-Dalgarno sequence and a slightly degenerated Pribnow-box. To confirm that the ORF delineated by computer really represents a protein, the protein NBRF database was searched for similarity. Using the FASTA program, 36.4\% identity over 165 aa was found with the hypothetical protein 1 of $A$. tumefaciens, a protein encoded by IS869 (Paulus et al., 1991). Similarly, $34 \cdot 2 \%$ identity was found over 76 aa of a $M$. tuberculosis transposase sequence available in the database but unpublished (accession no. S21394). Fig. 4 shows an alignment of the deduced amino acid sequence of the three proteins. There is a very strong conservation of residues in the middle of the putative transposase. Inspection of the alignment showed strict conservation of 14 contiguous residues and also a large number of identical residues and conservative replacements at other locations.

The putative protein contains a high number of basic residues. The calculated isoelectric point $(\mathrm{pI})$ of 11.35 suggests a possible interaction with nucleic acids. The propensity of the sequence to adopt definite secondary structures was analysed using the method of Garnier $e t$ al. (1978). The results clearly show a succession of $\alpha$ helices and $\beta$-sheets, suggesting an $\alpha / \beta$ structure. At the carboxy terminus of the molecule, a typical helix-turnhelix structure, thought to be the DNA binding site of the transposase (as discussed by Galas \& Chandler, 1989) was found (data not shown).

\section{Polymorphism revealed by IS6501 in the Brucella genome}

The presence of IS6501 in the nomen species of Brucella (B. abortus, B. canis, B. melitensis, B. ovis and B. suis) was investigated. Oligonucleotides were calculated in the IS fragment to design a PCR method that specifically detects IS6501. All the tested isolates exhibited an amplified fragment of the same expected size (data not shown). 
CGGTCGTGCATTTCAATAGGCTAGGGCTGTCTGCATTCAAGGATTCCCTITTGTACGAA
GATCCCGACACACGTAAGTCCTAAGGGAAACATGCTT
$\frac{-10}{\text { ATTCTGATTCAAGGTTTTAAAGGAGAACAGCCGTGAGCAGACGAAGCCTTACAGATGAG }}$ TAAGACTAAGTTCCAACAATTTCCTCTTGTCGGCACTGCTCTGCTTCGGAATGTCTACTC

$\begin{array}{lllllllllllllllllll}M & E & P & D & R & S & I & S & S & G & A & S & W & Y & A & R & P & Q & W\end{array}$ CAATGGAACCGGATCGAAGCATATCTTCCGGGGCGAGTTGGTACGCCCGGCCGCAGTGGG GTTACCTTGGCCTAGCTTCGTATAGAAGGCCCCGCTCAACCATGCGGGCCGGCGTCACCC

$\begin{array}{llllllllllllllllllll}V & D & N & R & L & F & V & D & A & I & L & W & M & A & A & N & A & G & T & G\end{array}$ TTGATAACCGATTATTTGTCGACGCCATCTTGTGGATGGCTGCCAATGCAGGCACTGGCG AACTATTGGCTAATAAACAGCTGCGGTAGAACACCTACCGACGGTTACGTCCGTGACCGC

$\begin{array}{llllllllllllllllllll}D & \text { L } & \text { P } & \text { A } & \text { T } & F & G & K & \text { W } & \text { T } & \text { A } & \text { V } & \text { H } & A & R & F & R & R & W & S\end{array}$ ATCTGCCTGCGACCTTCGGCAAATGGACAGCGGTTCATGCCCGCTTTCGGCGCTGGTCGC TAGACGGACGCTGGAAGCCGTTTACCTGTCGCCAAGTACGGGCGAAAGCCGCGACCAGCG

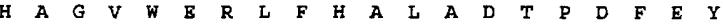
ACGCCGGTGTATGGGAAAGCTITTCCATGCCCTGGCTGATACGCCGGACTTTGAATATG TGCGGCCACATACCCTTTCCGAAAAGGTACGGGACCGACTATGCGGCCTGAAACTTATAC

$\begin{array}{lllllllllllllllllllll}V & L & I & D & S & T & I & S & K & V & H & A & D & A & A & G & A & K & G & G\end{array}$ TCCTCATTGATAGCACCATATCGAAAGTCCACGCAGATGCGGCGGGGCAAAAGGGGGGC AGGAGTAACTATCGTGGTATAGCTTTCAGGTGCGTCTACGCCGCCCGCGTTTTCCCCCCG

$\begin{array}{llllllllllllllllllll}I & K & L & P & A & S & V & S & R & G & G & I & T & T & K & L & H & A & V & V\end{array}$ TGAAGCTGCCTGCATCGGTCTCGCGCGGTGGATTGACGACCAAGCTGCATGCTGTTGTCG ACGTTCGAGGACGTAGCCAGAGCGCGCCACCTAACTGCTGGTTCGACGTACGACAACAGC

$\begin{array}{llllllllllllllllllll}D & A & I & G & L & P & L & R & I & K & P & T & P & G & H & Y & G & D & C & P\end{array}$ ATGCTATCGGCCTACCGCTGCGAATAAAGCCAACACCCGGCCATTATGGTGACTGTCCGC TACGATAGCCGGATGGCGACGCTTATTTCGGTTGTGGGCCGGTAATACCACTGACAGGCG

$\begin{array}{llllllllllllllllllll}\text { Q } & \text { A } & \text { S } & \text { S } & \text { L } & \text { L } & \text { S } & \text { G } & \text { L } & \text { K } & \text { G } & \text { V } & \text { G } & \text { H } & \text { V } & \text { L } & \text { A } & \text { D } & \text { A } & \text { A }\end{array}$ AAGCTTCAAGCCTTCTATCCGGCTTGAAGGGTGTGGGGCATGTCCTTGCTGATGCAGCCT TICGAAGTTCGGAAGATAGGCCGAACTTCCCACACCCCGTACAGGAACGACTACGTCGGA HindIII

Y D D H I R A F I A S N L K A T A O I ATGATGCCGATCACITAAGGGCCTTCATTGCCAGCAATCTCAAGGCAACGGCTCAGATCA TACTACGGCTAGTGAATTCCCGGAAGTAACGGTCGTTAGAGTTCCGTTGCCGAGTCTAGT

$\begin{array}{llllllllllllllllllll}K & V & N & P & T & R & S & S & V & P & T & I & D & W & R & \text { L } & Y & K & E & R\end{array}$ AGGTCAATCCAACACGTTCCAGTGTCCCAACAATCGACTGGAGGCTGTACAAGGAACGCC TCCAGTTAGGTTGTGCAAGGTCACAGGGTTGTTAGCTGACCTCCGACATGTTCCTTGCGG

$\begin{array}{llllllllllllllllllllll}H & Q & I & E & C & F & F & N & K & L & K & R & Y & R & R & I & A & L & R & C\end{array}$ ATCAGATTGAATGCTTITTTAACAAGTTGAAACGCTATCGTCGTATTGCGCTGCGATGCG TAGTCTAACTTACGAAAAAATTGTTCAACTITGCGATAGCAGCATAACGCGACGCTACGC

E $T$ I $T$ A $M$ G L $R$ S I S H A L AGAAAACATTGACCGCATTCATGGGGCTTCGGTCCATCTCGCATGCGCTATGATCTGGTT TCTIITGTAACTGGCGTAAGTACCCCGAAGCCAGGTAGAGCGTACGCGATACTAGACCAA

ACGTTGAATGCAGACACGCCCTAGAGCATTTCCAGCAAAAGCGT TGCAACTTACGTCTGTGCGGGATC

<............. -

Fig. 2. Nucleotide sequence of IS6501. Dashed arrows indicate the 17 base inverted repeats of the IS, with one mismatch $(*)$, and the $4 \mathrm{bp}$ target duplications are double-underlined. The HindIII site is also indicated. The site of insertion is at position 1750 of the BCSP31 gene. The deduced amino acid sequence of the putative transposase, indicated over the sequence in single-letter code, is obtained from the complementary strand with regard to the $5^{\prime} \rightarrow 3^{\prime}$ orientation of the BCSP 31 gene. The $-10,-35$ and the Shine-Dalgarno (SD) motifs are overlined. Five consensus sequences for Dam sites (GATC) and three consensus sequences for IHF are underlined (AANNNNTTGATA).

The possibilities of discriminating the different strains by RFLP, using IS6501 as a probe, were investigated. Southern blots of EcoRI-digested DNA of Brucella strains were probed with radiolabelled IS6501. Multiple banding patterns differentiated the strains into different RFLP types (Fig. 5). The differences in intensity of some $5^{\prime}$ element insertion site junction

$\begin{array}{lll}\text { PCR product } & \text { CGGTCGTGCATTTCAATAGGCTAG---- } & \text { IS6501 - } \\ \text { pBOH } 20 / 36 & \text { CGGTCCTGCATTTCAATAGGCTAG---- } & \text { IS6501 - } \\ \text { pBOH13/36 } & \text { GATTGAATCAGATCGGCGCTCTAG---- } & \text { IS6501 - } \\ \text { pBOH } 12 / 36 & \text { ATTGTGGGCATAGCCCCTCCCTAG---- } & \text { IS6501 - }\end{array}$

3 ' element insertion site junction

$\begin{array}{ll}\text { PCR product } & \text { - IS6501 ----CTAGAGCATTTCCAGCAAAAGCGT } \\ \text { pBOH10/37 } & \text { - IS6501 ----CTAGTGGATTGAATTTGACGTTTG } \\ \text { pBOH08/37 } & - \text { IS6501 ---CTAGAGCGCGTTTCGATCTGGTTG } \\ \text { pBOH } 11 / 37 & - \text { IS6501 ----CTAGAGCGCCGATCTGATTCAATC }\end{array}$

Fig. 3. Flanking sequences of isolated copies of IS6501. Designations of plasmids containing the different IS6501 copies are indicated. Direct repeats are in bold type. $\mathrm{pBOH} 20 / 36$ has the same sequence as the PCR-amplified fragment because it contains the BCSP31 gene.
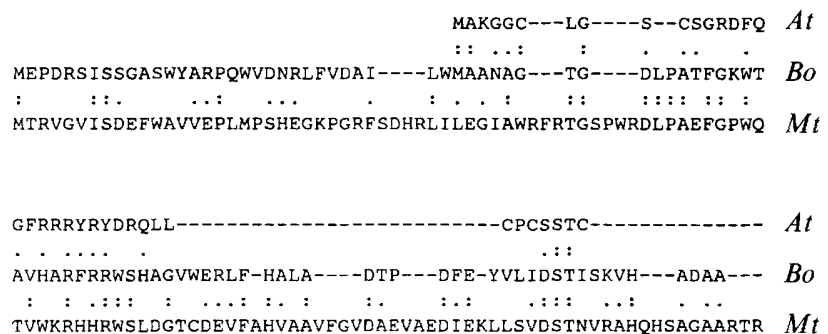
---GHGKKGDKHDGC-----MGRSRGGLTTKIHAVVDADGRPIRLALTAGQAHDGRMAEP At

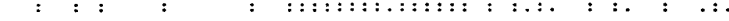 --GA-K-G----GLKLPASV--SRGGLTTKLHAVVDAIGLPLRIKPTPGHYGDCPQASS BO

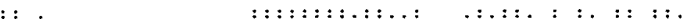
SPOGALSDYKKSADEPDDHAIGRSRGGLTTKI IHALTDQREAPVRI RLTAGQAGDNPQLLP $M t$

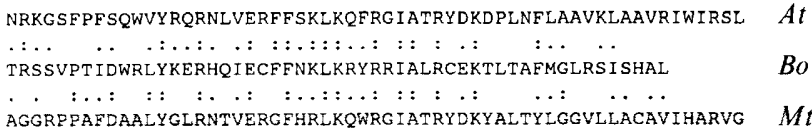

TPKLGDTP

Mt

Fig. 4. Homology between proteins encoded by IS 869 of $A$. tumefaciens (At), IS6501 of B. ovis (Bo) and the transposase of $M$. tuberculosis $(M t)$ (NBRF accession no. S21394). Dashes indicate gaps introduced to increase the number of matches. Identical and similar amino acids are represented by double and single dots, respectively.

of the bands may be due to a double band or to the presence of two or more copies of IS6501 in the fragment. Alternatively, the possibility of sequence heterogeneity within a strain cannot be excluded. These possibilities are under investigation. However, as expected, the results clearly show that an IS6501-based RFLP is able to discriminate between Brucella strains. 


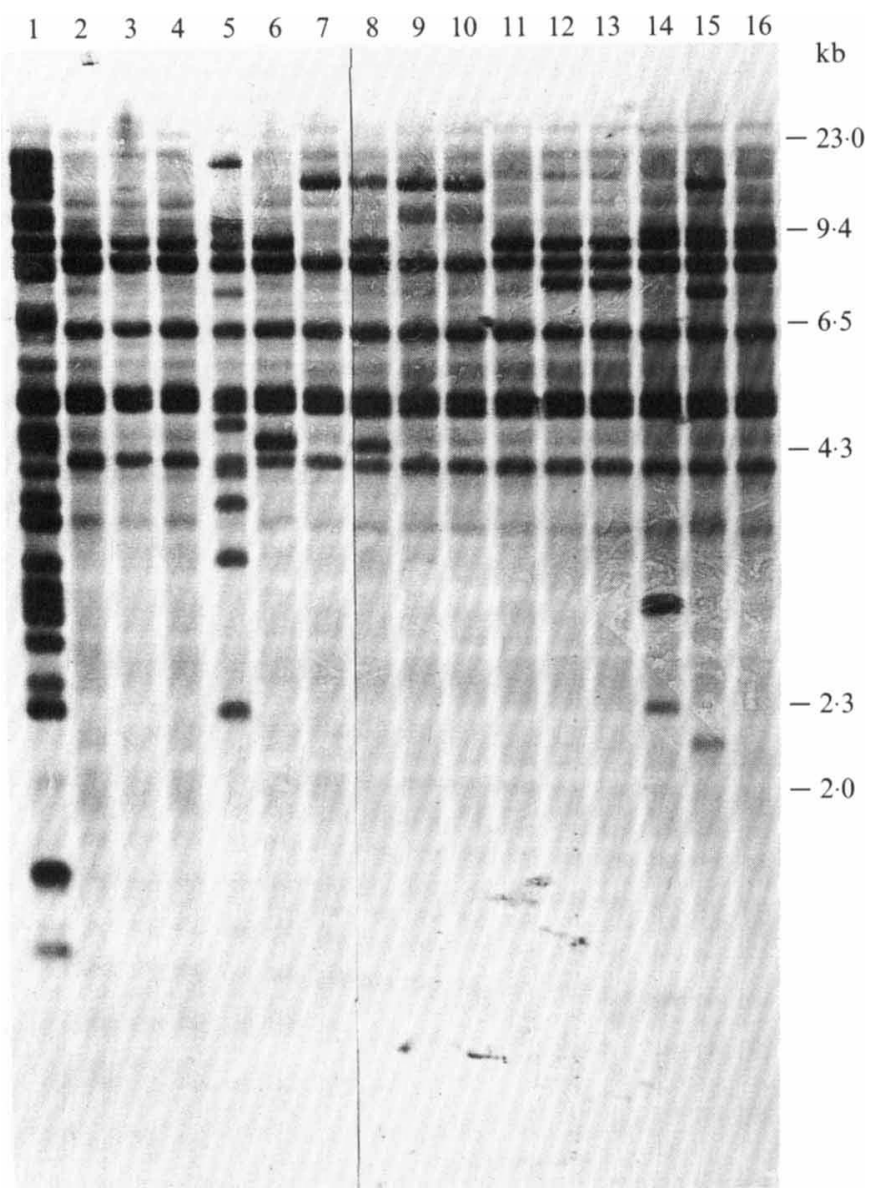

Fig. 5. Southern blot of EcoRI-digested DNA from several Brucella spp. probed with IS6501. Lanes: 1, B. ovis; 2, B. canis; 3, B. suis S4; 4, B. suis $\mathrm{S} 3 ; 5, B$. suis $\mathrm{S} 2 ; 6, B$. suis $\mathrm{S} 1 ; 7, B$. abortus $\mathrm{A} 9 ; 8, B$. abortus A6; $9, B$. abortus A5; 10, B. abortus A4; 11, B. abortus A3; 12, B. abortus A2; $13, B$. abortus A1; 14, B. melitensis M3; 15, B. melitensis M2; 16, B. melitensis M1.

\section{Comparison of B. melitensis and B. ovis strains by PFGE}

Because of the polymorphism revealed by RFLP using IS6501 as a probe, it was interesting to compare this finding with the polymorphism revealed by PFGE. For this purpose, genomic DNA isolated from the reference strain and seven field strains belonging to biovar 3 of $B$. melitensis were digested by $X b a \mathrm{I}$ and the fragments were separated by PFGE. The reference strain and nine field isolates of $B$. ovis were also analysed in the same manner. As in our previous studies (Allardet-Servent et al., 1988), no difference could be demonstrated between the field strains of $B$. melitensis biovar 3 (data not shown). The electrophoretic pattern of the B. ovis isolates appeared to be very similar (data not shown). Nevertheless, four patterns could be distinguished, differing by one or two bands: pattern I contains three strains (208, 212 and 217, all isolated near Bilbao, Spain); pattern II contains one strain (247, isolated near Toulon, France); pattern III

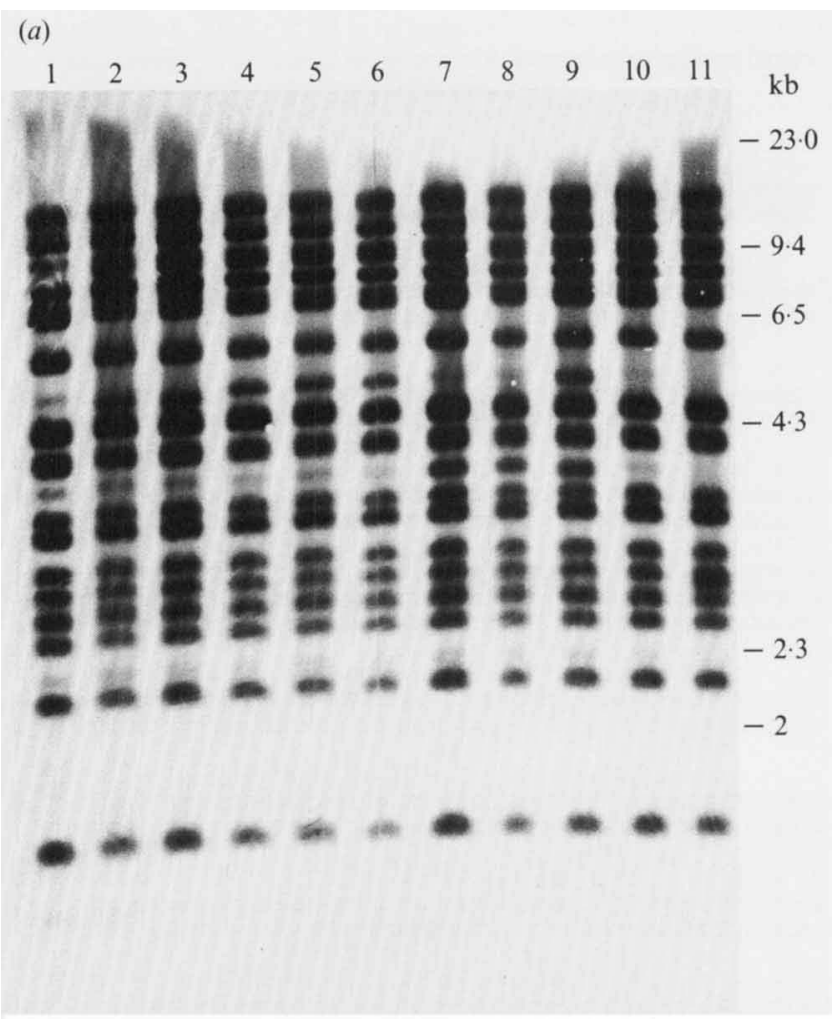

(b)

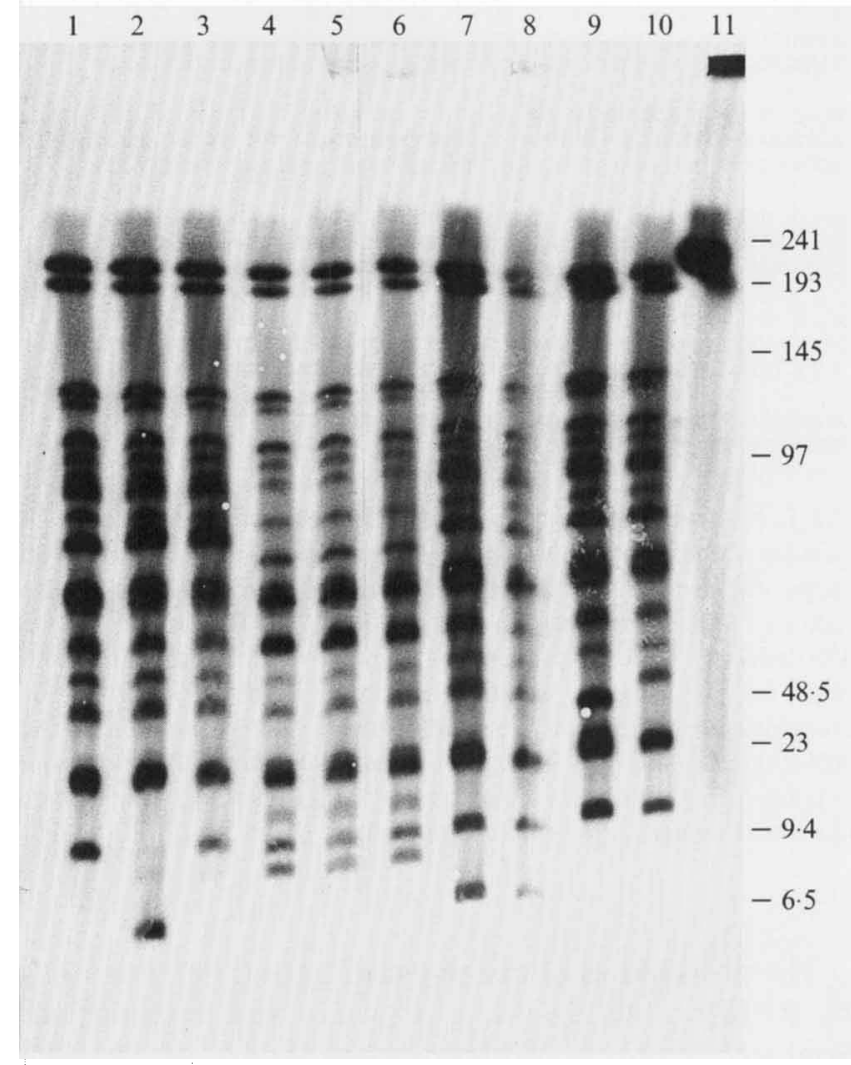

Fig. 6. Southern blot of EcoRI- (a) and XbaI- (b) digested DNA from reference and field strains of Brucella ovis probed with IS6501. Lanes: $1,91 / 268 ; 2,91 / 266 ; 3,91 / 264 ; 4,91 / 217 ; 5,91 / 212 ; 6,91 / 208 ; 7$, $91 / 170 ; 8,91 / 66 ; 9,76 / 247 ; 10,76 / 250 ; 11, \mathrm{RM} / 66^{\mathrm{T}}$ (ATCC 25840). 
contains one strain (268, isolated in Switzerland); pattern IV contains all the other strains (isolated in Argentina, Spain or France).

\section{Comparison of B. melitensis and B. ovis strains by} hybridization with IS650I

Genomic DNA from the same strains were digested with $E c o$ RI and $X b a \mathrm{I}$. The fragments were separated either by conventional methods $(E c o$ RI) or by PFGE (XbaI) and blotted onto nylon membranes which were then hybridized with the IS6501 probe. No differences could be demonstrated within the $B$. melitensis strains (data not shown). Among the $B$. ovis isolates, five hybridization patterns were observed, differing by one or two bands in the digests with EcoRI and seven bands in the digests with $X b a \mathbf{I}$ (Fig. 6). However, the grouping of the strains was different when DNA was digested by EcoRI or by $X b a \mathrm{I}$ : the Bilbao group (strains 208,212,217) and strain 247 , both individualized by PFGE, always exhibited a unique pattern; strains 66 and 70 (isolated in Aragon, Spain) were individualized by the two methods, but strain 250 (isolated near Biarritz, France), 264 and 266 (isolated in Argentina), and 268 (isolated in Switzerland) were distinguishable by IS6501 hybridization on EcoRI and $\mathrm{XbaI}$ fragments.

\section{Discussion}

This study reports the identification, cloning and characterization of an IS from $B$. ovis called IS6501. It was first identified downstream of the coding sequence of BCSP31 described by Mayfield et al. (1988) at position 1750.

To determine precisely the sequence of this element, the sequence of other copies of IS6501, identified from a genomic bank, was also determined. The sequence is conserved in all the sequences determined of the various copies of the IS6501 of B. ovis. Analysis and comparison of the nucleotide sequence of different clones identified in the library showed that IS6501 has 4 bp duplicated at the insertion site and the presence of inverted repeats has been assessed. Concerning the flanking regions of this IS, no specific consensus sequence for its integration in the genome was found. These data confirmed that the postulated IS contains all the structural and biological transposition characteristics of a prokaryotic IS element.

Analysis of the sequence of IS6501 revealed five Dammethylase sites and three IHF sites (Fig. 2). The search for a specific Dam-methylase in Brucella was negative, thus it is difficult to know if this sequence is meaningful. In contrast, the three IHF sites are localized near the end (but not at the end) of IS6501. IHF sequences have been reported at the end of E. coli IS1 (Gamas et al., 1987), near the end of IS10 and within the sequence of numerous ISs (for a review, see Galas \& Chandler, 1989). A role in transposition has been suggested, however inspite of suggestive observations, no convincing effect in vivo has been obtained with ISI (Galas \& Chandler, 1989). Similarly, an IHF site present near one of the ends of Tn 1000 binds IHF cooperatively with the transposase at an adjacent site and, in vitro, IHF binding enhances transposase binding (Grindley \& Wiater, 1988). However, IHF-negative mutant strains support apparently normal Tn 1000 transposition. The presence of IHF sites is common in many ISs, but their exact role remains to be established.

The larger ORF encodes a protein rich in basic amino acids, with a calculated pI of 11.35 , and a predicted secondary structure compatible with a helix-turn-helix motif, suggesting a possible interaction with DNA (for a review, see Galas \& Chandler, 1989). Furthermore, homologies with a transposase from Mycobacterium confirm that in Brucella this ORF certainly encodes a transposase.

IS650I is present in all species and strains of Brucella tested. The existence of a genus-specific IS might have important theoretical and practical consequences. The homology with $A$. tumefaciens is highly significant and argues in favour of the phylogenetic proximity between these bacteria. This observation is in agreement with evolutionary analysis based on the chemical analysis of the lipid A fraction (Moreno et al., 1990) and 16S rRNA (Weisburg et al., 1991). Both belong to the Alpha-2 subdivision of the class Proteobacteria (Woese et al., 1984), containing many bacteria that form intimate pericellular or intracellular associations with eukaryotic cells. The finding of a related IS in both organisms confirms the close relationship between them. However, there are two ways of explaining the homology of the IS observed in the two genera: the IS may have existed either before the separation of the two genera or a horizontal transfer may have occurred later after the separation. If the first hypothesis is true, then this IS should constitute a molecular marker to construct a phylogenetic tree among these bacteria. The second hypothesis is more problematic and cannot be proved in the light of our present knowledge.

ISs are mobile elements. Transposition of IS leads to several genetic events such as deletion or inversion (Galas \& Chandler, 1989), introducing great variability in the genome. On this basis, IS fingerprinting was proposed as a typing method for an epidemiological survey of bacterial infections (Glare et al., 1990; Hermans et al., 1990). The copy number of ISs varies widely from strain to strain within the same species. For instance, in a sample of 71 independent isolates of $E$. coli (the ECOR collection), 11 did not carry genomic copies 
of IS 1 , whilst 16 carried between 10 and 40 copies (Galas $\&$ Chandler, 1989). However, the copy number of ISs is usually lower, since the average copy number in these 71 E. coli strains was determined to be 6.4 for IS $1,2.7$ for IS 3, 2 for IS4, 1.3 for IS5, and 0.9 for IS30. The genomic location could be associated with specific pathogenicity for a preferential host (Mills et al., 1992). The copy number of the IS6501 sequence is moderately high in Brucella and varies in the different species. It was determined to be $7-10$ in the three biovars of $B$. melitensis, $6-8$ in the seven $B$. abortus biovars, as in the four $B$. suis biovars and in B. canis, and more than 28 in B. ovis. Moreover, IS fingerprinting showed that the genomic localization of IS6501 is species-specific, confirming at the genomic level the species and the biovars described in the genus by phenotypic methods, as it was found previously with PFGE. However, RFLP revealed by PFGE or by IS hybridization is not sufficient to identify a given strain at the species or subspecies level. More probably, differences in restriction or hybridization patterns are likely to be related to evolving lineages within the genus. In our study, IS6501 localization on the genome was compared in $B$. melitensis and $B$. ovis isolates, including reference and field strains. Two main differences were observed between the two species. Firstly, the copy number of the IS is very different in the genomes of the two species since $B$. ovis contains three times more copies than $B$. melitensis. Secondly, in contrast to the polymorphism demonstrated by PFGE or IS6501 hybridization in B. ovis (our results and Halling \& Zehr, 1990), surprisingly no differences were seen between the $B$. melitensis isolates tested by either method.

The polymorphism observed by PFGE of DNA fragments generated by rare cutting restriction endonucleases can be explained either by mutations affecting the restriction sites or by chromosomal rearrangements. The correlation between high copy number of the IS and the polymorphism demonstrated by digestion of the genomic DNA with rare cutting enzymes suggests that the differences observed by PFGE may be more related to chromosomal rearrangements than mutations. This may be mediated at least partly by IS transposition. Several authors have proposed such a mechanism for PFGE polymorphism observed in Bacillus cereus or Clostridium perfringens strains by other arguments, such as physical mapping of chromosomes of different strains belonging to the same species (Carlson et al., 1992; Canard et al., 1992). This proposal is strengthened by the results of IS6501 hybridization on EcoRI or $X b a \mathrm{I}$ fragments from $B$. ovis DNA, which showed only two polymorphic bands with the first endonuclease and at least seven with the second.

The simplest explanation of the differences in copy number observed in the two Brucella species is that
IS6501 is always active in $B$. ovis leading to the polymorphism observed in the species, and inactive in $B$. melitensis, in which the IS would be unable to transpose. This implies that the positions of insertions in the $B$. melitensis genome are conserved in the other species. This seems to be the case when one examines the gels (not shown). Indeed, most of the bands present in $B$. melitensis also appear in other species.

ISs are responsible for a number of genetic rearrangements, including gene inactivation by insertional mutagenesis or deletion, gene activation by insertion or formation of upstream promoters, or plasmid integration (Iida et al., 1983; Galas \& Chandler, 1989). The presence of IS6501 may confer a possible selective advantage to the organism such as altered pathogenicity or modified host specificity. It is noteworthy that $B$. ovis is an avirulent species for humans and it contains the highest IS copy number. The existence of altered virulence due to an IS has been reported in other pathogenic bacteria (Mills et al., 1992).

For practical purposes, genus-specific elements such as IS6501 might be useful as molecular probes for the identification of clinical isolates. We are currently developing PCR methodology for specific and sensitive detection of Brucella to complement the method described by Fekete et al. $(1990 a, b)$. As IS6501 is present as multicopies in the Brucella genome, this will increase the sensitivity of detection. Such PCR assays will be useful for the detection of infectious Brucella in the veterinary field and in dairy products. When used as a probe, IS6501-based RFLP is able to distinguish between Brucella species and strains.

We are grateful to Drs B. Andral and J. Verger for the gifts of the Brucella strains. Thanks are due to Drs G. Travé and D. O'Callaghan and Professor J. L. Cuq for their enlightening discussions. This work was supported by grants from Recherche et Partage and from the Caisse Nationale d'Assurance Maladie.

\section{References}

Allardet-Servent, A., Bourg, G., Ramuz, M., Pages, M., Bellis, M. \& RoIzEs, G. (1988). DNA polymorphism in strains of the genus Brucella. Journal of Bacteriology 170, 4603-4607.

Allardet-Servent, A., Carles-Nurit, M. J., Bourg, G., Michaux, S. \& Ramuz, M. (1991). Physical map of the Brucella melitensis 16M chromosome. Journal of Bacteriology 173, 2219-2224.

Ausubel, F. M., Brent, R., Kingston, R. E., Moore, D. D., Seidman, J. G., Smith, J. A. \& Struhl, K. (1987). Current Protocols in Molecular Biology, vol. 1. New York: Wiley Interscience.

Canard, B., St-Joanis, B. \& Cole, S. T. (1992). Genomic diversity and organization of various genes in the pathogenic anaerobe Clostridium perfringens. Molecular Microbiology 6, 1421-1429.

Carlson, C. R., Gronsdat, A. \& Kolsto, A. B. (1992). Physical maps of the genomes of three Bacillus cereus. Journal of Bacteriology 174, 3750-3756

Cellier, M., Teyssier, J., Nicolas, M., Liautard, J. P., Marti, J. \& SRI WIDADA, J. (1992). Cloning and characterization of the Brucella ovis heat shock protein DnaK functionally expressed in $E$. coli. Journal of Bacteriology 174, 8036-8042. 
Corbel, M. J. \& Brinley-Morgan, W. J. (1984). Genus Brucella Meyer and Shaw 1920 173AL. In Bergey's Manual of Systematic Bacteriology, vol. 1, pp. 377-388. Edited by N. R. Krieg \& J. G. Holt. Baltimore: Williams \& Wilkins.

De Meirsman, C., Van Soom, C., Verreth, C., Van Gool, A. \& VANDERLEYDEN, J. (1990). Nucleotide sequence analysis of IS427 and its target sites in Agrobacterium tumefaciens T37. Plasmid 24, 227-234.

Dessen, P. Fondrat, C., Valencien, C. \& Mugnier, C. (1990). BISANCE: a French service for access to biomolecular sequence data bases. CABIOS 6, 335-356.

Fekete, A., Bantle, J. A., Halling, S. \& Sanborn, M. R. (1990a). Preliminary development of a diagnostic test for Brucella using polymerase chain reaction. Journal of Applied Bacteriology 69, 216-227.

Fekete, A., Bantle, J. A., Halling, S. \& Sanborn, M. R. (1990b). Rapid, sensitive detection of Brucella abortus by polymerase chain reaction without extraction of DNA. Biotechnology Techniques 4 , 31-34.

Galas, I. \& Chandler, M. (1989). Bacterial insertion elements. In Mobile DNA, pp. 109-162. Edited by D. E. Berg \& M. M. Howe. Washington, DC: American Society for Microbiology.

Gamas, P., Chandler, M., Prentki, P. \& Galas, I. (1987). Escherichia coli integration host factor binds specifically to the ends of the insertion sequence IS 1 and to its major hot-spot in pBR322. Journal of Molecular Biology 195, 261-272.

Garnier, J., Osguthorpe, A. \& Robson, B. (1978). Analysis of the accurance and implication of simple methods for predicting the secondary structure of globular proteins. Journal of Molecular Biology 120, 97-120.

Glare, E. M., Paton, J. C., Premier, R. R., Lawrence, A. J. \& NisBET, I. T. (1990). Analysis of a repetitive DNA sequence from Bordetella pertussis and its application to the diagnosis of pertussis using the polymerase chain reaction. Journal of Clinical Microbiology 28, 1982-1987.

Grindley, N. D. \& Wiater, L. A. (1988). gd transposase and integration host factor bind cooperatively at both ends of gd. $E M B O$ Journal 7, 1907-1912.

Halling, S. \& ZeHr, E. (1990). Polymorphism in Brucella spp. due to highly repeated DNA. Journal of Bacteriology 172, 6637-6640.

Hermans, P. W. M., van Soolingen, D., BiK, E. M., Dehaas, P. E. W., Dale, J. W. \& Van Embden, J. D. A. (1990). Insertion element IS987 from Mycobacterium bovis BCG is located in a hot- spot integration region from insertion elements in Mycobacterium tuberculosis complex strains. Infection and Immunity 59, 2695-2705.

IIdA, S., Meyer, J. \& ARber, W. (1983). Prokaryotic IS elements. In Mobile Genetic Elements, pp. 159-221. Edited by J. A. Shapiro. San Diego: Academic Press.

Mayfield, J. E., Bricker, B. J., Godfrey, H., Crosby, R. M., KNiGht, D. J., Halling, S. M., Balinsky, D. \& Tabatai, L. B. (1988). The cloning, expression, and nucleotide sequence of a gene coding for an immunogenic Brucella abortus protein. Gene 63, 1-9.

MEYER, M. E. \& CAMERON, H. S. (1961). Metabolic characterization of the genus Brucella. I. Statistical evaluation of the oxidative tests by which type 1 of each species can be identified. Journal of Bacteriology 82, 387-395.

Michaux, S., Paillisson, J., Carles-Murit, M. J., Bourg, G., Allardet-Servent, A. \& Ramuz, M. (1993). Presence of two independent chromosomes in the Brucella melitensis $16 \mathrm{M}$ genome. Journal of Bacteriology 175, 701-705.

Mills, J. A., Venkatesan, M. M., Baron, L. \& Buysse, J. M. (1992). Spontaneous insertion of an IS $I$-like element into the virF gene is responsible for avirulence in opaque colonial variants of Shigella flexneri 2a. Infection and Immunity 60, 175-182.

Moreno, E., Stackebrandt, E., Dorsh, M., Wolters, J., Bush, M. \& MAYER, H. (1990). Brucella abortus 16S rRNA and Lipid A reveal a phylogenetic relationship with members of the Alpha-2 subdivision of the class Proteobacteria. Journal of Bacteriology 172, 3569-3576.

Paulus, F., Canady, J., Vincent, F., Bonnard, G., Kares, C. \& OtTEN, L. (1991). Sequence of the iaa and ipt region of different Agrobacterium tumefaciens biotype III octopine strains: reconstruction of octopine Ti plasmid evolution. Plant Molecular Biology $16,601-614$

Sambrook, J., Fritsch, E. F. \& Maniatis, T. (1989). Molecular Cloning: a Laboratory Manual, 2nd edn. Cold Spring Harbor, NY: Cold Spring Harbor Laboratory.

Verger, J. M., Grimont, F., Grimont, P. A. D. \& Grayon, M. (1985). Brucella, a monospecific genus as shown by deoxyribonucleic acid hybridization. International Journal of Systematic Bacteriology 35, 292-295.

Weisburg, W., Barns, S. M., Pelletier, D. A. \& Lane, D. L. (1991). 16 S ribosomal DNA amplification for phylogenetic study. Journal of Bacteriology 173, 697-703.

Woese, C. R., Stackebrandt, E., Weisburg, W. G., Paster, B. J., Madigan, M. T., Fowler, R. V. J., Hahn, C. M., Blanz, P., Gupta, R., Nealson, K. H. \& Fox, G. E. (1984). The phylogeny of purple bacteria: the alpha subdivision. Systematic and Applied Microbiology 5, 315-326. 